\title{
Estudo sobre a Viabilidade da Implantação Formal do Ensino de Empreendedorismo na Rede Municipal de Ensino Fundamental no Município de Vassouras-RJ
}

\author{
Tatiana Nunes Coelho Ramos \\ USS-CELCSAH - Gestão Pública Municipal-tncramos@hotmail.com \\ Margareth Fernandes \\ USS -CELCSAH - Gestão Pública Municipal-fernandes.meg@gmail.com
}

\begin{abstract}
Resumo: $O$ avanço tecnológico e a globalização são apontados como os principais eixos de mudanças na atualidade. Essas mudanças, que ocorrem em velocidade superior às demais épocas, exigem dos homens comportamentos e habilidades eficazes na produção da vida. A teoria do empreendedorismo é um caminho de possibilidades para o desenvolvimento de novas habilidades que instrumentalizam os homens nesse processo de mudança. A educação, um dos motores que mais contribui para o crescimento economico do país deve preparar o indivíduo para as mudanças no mundo do trabalho. Contudo, as dificuldades e os problemas gerados de forma intensa em periodos de transformação, podem ser empecilhos para a construção social diferenciada. Somente com o desenvolvimento de nova práxis o homem poderá fazer frente às novas exigências. Acreditando na possibilidade de disseminar o espírito empreendedor no ambiente escolar, proporcionando o desenvolvimento de habilidades empreendedoras em crianças e adolescentes, o presente trabalho se originou. A idéia de desenvolver uma educação empreendedora fez com que fossem criados procedimentos metodológicos direcionados ao desenvolvimento de habilidades empreendedoras em crianças no Ensino Fundamental da rede municipal de educação.
\end{abstract}

Palavras-chave: Empreendedorismo. Escola. Ensino fundamental.

\section{Feasibility Study on the Implementation of the Formal Education of Entrepreneurship in the Municipal Elementary School in the Municipality of Vassouras-RJ}

Abstract: Technological advances and globalization are identified as the main axes of change today. These changes, which occur more rapidly than at 
Estudo sobre a Viabilidade da Implantação Formal do Ensino de Empreendedorismo na Rede Municipal de Ensino Fundamental no Município de Vassouras-RJ Tatiana Nunes Coelho Ramos - Margareth Fernandes

Artigo de Demanda Contínua

other times, men's behavior and require effective skills in the production of life. The theory of entrepreneurship is a path of possibilities for developing new skills that instrumentalize men in the process of change. Education is an engine that contributes most to the country's economic growth should prepare individuals for the changing world of work. However, the difficulties and problems generated so intense period of transformation, may be obstacles to building social identity. Only with the development of new practice man can cope with the new requirements. Believing in the possibility of spreading the entrepreneurial spirit in the school environment, encouraging the development of entrepreneurial skills in children and adolescents, this work originated. The idea of developing an entrepreneurial education has caused to be established methodological procedures directed to the development of entrepreneurial skills among children in elementary education from the municipal education.

Keywords: Entrepreneurship. School. Elementary school.

\section{Introdução}

Diante das dificuldades encontradas no ambiente escolar e das possibilidades de superar os desafios de modo inovador, o presente estudo visa comprovar as possibilidades de desenvolver habilidades empreendedoras em crianças e adolescentes do Ensino Fundamental, gerando nos alunos comportamentos novos. A relevância da habilidade de empreender permite que o tema seja propagado e ensinado em outras áreas de formação profissional que exijam a capacidade de criação e de ajustes frente as mudanças aceleradas do ambiente e essas mudanças fazem com que paradigmas sejam quebrados. Hoje a economia mundial opera com novos padrões de relação de trabalho onde a estabilidade profissional se posiciona longe da realidade encontrado no mercado de trabalho. Por este motivo e por estar em contato direto com essa realidade do empreendedorismo formal e informal e a preocupação do ensino, espírito e cultura "Empreendedora", tanto para a micro como pequena empresa, quanto para o conhecimento interno e também por trabalharmos em empresas altamente empreendedoras como o Balcão SEBRAE/Vassouras e uma concessionária de energia elétrica Light, é que realizamos esse estudo para tentarmos juntamente com o Poder Executivo local e demais instituições parceiras do Município de Vassouras, tornar possível essa implantação. Nesse contexto, a intervenção pedagógica assume fundamental participação no desenvolvimento de cidadãos empreendedores, capazes de ensiná-los a conviver e sentir, pois o saber conviver implica a colaboração com o outro para que sejam enfrentadas e negociadas as adversidades, ampliando suas possibilidades de inserção e preservação profissional, bem como, social. As instituições de ensino têm como principal desafio formar um ser social, com habilitações técnicas e científicas, consciente de seu papel civil, e capaz de contribuir para a melhoria da qualidade de vida do homem. Para tal, o aluno deve estar no centro do processo de ensino, e deve ser visto como cliente, e, como pessoa ao mesmo tempo. Ele deve ser visto como ponto de partida e de chegada. Então, tudo terá valido a pena, se o aluno aprender. Sob este enfoque, o presente trabalho, defende uma abordagem pedagógica com base na formação 
Estudo sobre a Viabilidade da Implantação Formal do Ensino de Empreendedorismo na Rede Municipal de Ensino Fundamental no Município de Vassouras-RJ

Tatiana Nunes Coelho Ramos - Margareth Fernandes

Artigo de Demanda Contínua

de empreendedores, onde os professores, além de se preocuparem com a formação integral dos seus alunos, devem considerar as suas aptidões individuais, suas múltiplas inteligências, e assim, trabalhar no sentido de aprimorá-las e desenvolvê-las.

\section{Empreendedorismo e Empreendedor}

\section{Definições}

O empreendedorismo é tido como um comportamento ou um processo para iniciar e desenvolver um negócio ou um conjunto de atividades com resultados positivos, portanto, é a criação de valor através do desenvolvimento de uma organização (Smith, 1981) No que se refere à palavra empreendedor foi utilizada pela primeira vez na língua francesa no início do século XVI, para designar os homens envolvidos na coordenação de operações militares. Mais tarde, por volta de 1765 o termo começou a ser utilizado na França para designar aquelas pessoas que se associavam com proprietários de terras e trabalhadores assalariados. Somente em 1911, com a publicação da obra Teoria do Desenvolvimento Econômico de Schumpeter (1985), é que a conotação de empreendedor adquiriu um novo significado. Segundo este autor, [...] O empreendedor é o responsável pelo processo de destruição criativa, sendo o impulso fundamental que aciona e mantém em marcha o motor capitalista, constantemente criando novos produtos, novos métodos de produção, novos mercados e implacavelmente, sobrepondo-se aos antigos métodos menos eficientes e mais caros (Schumpeter, 1985, p. 52).

Para Drucker (2002), os empreendedores são pessoas que inovam. "A inovação é o instrumento especifico dos empreendedores, o meio pelo qual eles exploram a mudança como uma oportunidade para um negócio ou serviço diferente". O empreendedor sempre está buscando a mudança, reage a ela e a explora como sendo uma oportunidade. $\mathrm{O}$ empreendedor tem a personalidade criativa, sempre lidando melhor com o desconhecido, perscrutando o futuro, transformando possibilidades em probabilidades e caos em harmonia; é alguém que sabe onde, quando e como chegar na busca da sua realização pessoal, de sua família, empresa ou comunidade e, uma vez definidos os seus sonhos, ele os projeta com um horizonte futuro de aproximadamente quinze (15) anos. Enquanto muitos deixam os seus sonhos reféns das dificuldades do momento atual, (às vezes até perdendo a capacidade de sonhar), o Empreendedor procura agir sobre a realidade presente afim de transformá-la ou adequá-la a serviço do seu futuro ou dos seus objetivos.

\section{Desenvolvimento da cultura empreendedora}

A educação para o empreendedorismo está se tornando um componente importante na integração dos programas acadêmicos de universidades e escolas, com nítida tendência a expansão propelida pelas forças sócio-econômicas. A demanda por ocupações vinculadas ao auto-emprego ou empreendimento próprio está refletida no crescente número de universidades que iniciaram novas disciplinas ou programas relacionados com empreendedorismo, tais como centenas delas no exterior e algumas no Brasil, notadamente como a Universidade de São Paulo (USP), Universidade Federal de Santa Catarina 
Estudo sobre a Viabilidade da Implantação Formal do Ensino de Empreendedorismo na Rede Municipal de Ensino Fundamental no Município de Vassouras-RJ Tatiana Nunes Coelho Ramos - Margareth Fernandes

Artigo de Demanda Contínua

(UFSC), Universidade Federal de Pernambuco e Universidade de Brasília (UnB).

Visualizamos o emergir de uma economia baseada em pequenos e médios negócios o que nos leva a realçar a necessidade de preparar e educar potenciais empreendedores para que identifiquem oportunidades, equipando-os com os conhecimentos e as habilidades necessárias ao gerenciamento destas oportunidades com redução dos riscos e da probabilidade de fracasso. Neste contexto, as universidades têm um papel a desempenhar e uma oportunidade para empreender.

Nenhum curso, certamente, pode garantir, na fase atual da história do empreendedorismo, que os indivíduos educados em empreendedorismo serão melhores empreendedores do que aqueles que não tenham recebido nenhuma formação nesta área, somente porque estudaram empreendedorismo. Em contrapartida, é difícil que alguém possa fazer comparações acerca das inúmeras disciplinas que um indivíduo tem de cursar, num programa de formação de gestores e as que compõem um curso de preparação de empreendedores. Entretanto, existem fortes indicações de que uma educação empreendedora produzirá mais e melhores empreendedores do que os que foram gerados no passado.

\section{Perfil do empreendedor de sucesso}

A grande pergunta que os pesquisadores se fazem é "quais são as características dos empreendedores de sucesso? Eles têm algo diferente dos outros?". Hoje há muita concordância entre os cientistas sobre as características dos empreendedores de sucesso, traços de personalidade, atitudes e comportamentos que ajudam a alcançar êxito nos negócios.

De acordo com Timmons (1994) e Hornaday (1982) citados por Silva et al, 2001), as características dos empreendedores de sucesso são:

... o empreendedor tem um "modelo", uma pessoa que o influencia; tem iniciativa, autonomia, autoconfiança, otimismo, necessidade de realização;

- trabalha sozinho;

- tem perseverança e tenacidade;

- o fracasso é considerado um resultado como outro qualquer. $\mathrm{O}$ empreendedor aprende com os resultados negativos, com os próprios erros;

- tem grande energia. É um trabalhador incansável; é capaz de se dedicar intensamente e sabe concentrar os seus esforços para alcançar resultados;

- sabe fixar metas e alcançá-las. Luta contra padrões impostos. Diferencia-se. Tem a capacidade de ocupar um intervalo não ocupado por outros no mercado, descobrir nichos; (Silva et al, 2001, p. 43).

\section{Porque o ensino de empreendedorismo}

O ensino do empreendedorismo durante a formação de um novo profissional tem sido considerado pelos especialistas como vital para o seu sucesso, principalmente se ele for egresso das escolas ditas de massa. Estas instituições concebem seu projeto pedagógico 
baseado em novos paradigmas educacionais e no desenvolvimento das competências para o trabalho, considerando todas as peculiaridades e incertezas da sociedade do século XXI. Hoje, o ensino de empreendedorismo no primeiro grau tornou-se obrigatório em cinco estados americanos. O contexto que emoldura estas considerações é o de que, depois da Segunda Guerra, 50\% de todas as inovações e 95\% de todas as inovações radicais vieram de empresas novas e pequenas. Sendo assim, o empreendedorismo se estabelece como um fenômeno cultural, e portanto, fortemente relacionado e embasado no processo educacional, capaz de impulsionar a criação de pequenas e médias empresas inovadoras de base tecnológica (Pessoa et alii, 2010). Atualmente, em diversas escolas já estão incluindo nos seus currículos a disciplina de empreendedorismo, estimulando e favorecendo a criação de novos empreendimentos. E o ensino do empreendedorismo é apontado como prioridade na política governamental de qualquer país que queira desenvolver inovações tecnológicas e, com isso, objetive constituir-se em uma economia competitiva no mundo globalizado. Enfim, o ensino do empreendedorismo é importante por várias razões, conforme descrito por Dolabela (1999):

$[\ldots]$

Razão 1 - A alta taxa de mortalidade infantil. No mundo das empresas emergentes a regra é falir, e não ter sucesso. De cada três empresas criadas, duas fecham as portas. As pequenas empresas (menos de 100 empregados) fecham mais: 99\% das falências são de empresas pequenas. Se alguns têm sucesso sem qualquer suporte, a maioria fracassa, muitas vezes desnecessariamente. A criação de empresas é um problema de crescimento econômico.

Razão 2 - No final do século XX e início do século XXI, as relações de trabalho estão mudando. O emprego dá lugar a novas formas de participação. Na verdade as empresas precisam de profissionais que tenham umas visões globais do processo, que saibam identificar e satisfazer as necessidades do cliente. A tradição do nosso ensino é de formar empregados, nos níveis universitário e profissionalizante, não é mais compatível com a organização da economia mundial.

Razão 3 - Exige-se hoje, mesmo para aqueles que vão ser empregados, um alto grau de empreendedorismo. As empresas precisam de colaboradores que, além de dominar a tecnologia, conheçam também o negócio, saibam auscultar, atender as necessidades do cliente e possam identificar oportunidades, e mais, buscar e gerenciar os recursos para viabilizá-las.

Razão 4 - A metodologia de ensino tradicional não é adequada para formar empreendedores.

Razão 5 - As nossas instituições de ensino estão distanciadas dos "sistemas de suporte", ou seja, das empresas, órgãos governamentais, financiadores, associações de classe, entidades das quais os pequenos empreendedores dependem para sobreviver. As relações universidade-empresa ainda são incipientes no Brasil.

Razão 6 - Cultura. Os valores do nosso ensino não sinalizam para o empreendedorismo.

Razão 7 - Ainda há uma percepção insuficiente da importância da PME (Pequena e Média Empresa) para o desenvolvimento econômico. 
Estudo sobre a Viabilidade da Implantação Formal do Ensino de Empreendedorismo na Rede Municipal de Ensino Fundamental no Município de Vassouras-RJ

Tatiana Nunes Coelho Ramos - Margareth Fernandes

Artigo de Demanda Contínua

Razão 8 - Predomina, no ensino profissionalizante e universitário, a cultura da "grande empresa". Não há o hábito de se falar na pequena empresa. Os cursos de administração, com raras exceções são voltados quase exclusivamente para o gerenciamento de grandes empresas.

Razão 9 - Ética - Uma grande preocupação no ensino do empreendedorismo devem ser os aspectos éticos que envolvem esta atividade. Por sua grande influência na sociedade e na economia, é fundamental que os empreendedores - como qualquer cidadão - sejam guiados pelos princípios e valores nobres.

Razão 10 - Cidadania. O empreendedor deve ser alguém com alto comprometimento com o meio ambiente e com a comunidade, com forte consciência social. A sala de aula é um excelente lugar para o debate desses termos (Dolabela, 1999, p. 53)

\section{Fatores de Sucesso}

Segundo Timmons (1994) citado por Silva et al, (2001) existem alguns fatores que levam ao sucesso, como por exemplo, fazer o que lhe dá energia; divertir-se; imaginar como fazer funcionar algo; dizer "posso fazer" ao invés de "não posso" ou "talvez"; tenacidade e criatividade irão triunfar; qualquer coisa é possível se você acredita que pode fazê-la; se você não sabe que não pode ser feito, então vá em frente e o fará; veja o copo metadecheio e não metade-vazio; seja insatisfeito com o jeito que as coisas estão e procure melhorá-las; faça coisas de forma diferente; não assuma riscos se você não precisa, mas assuma um risco calculado se é a oportunidade certa para você; os negócios fracassam; os empreendedores de sucesso aprendem, mas tente manter baixo o custo do aprendizado; faça da oportunidade e dos resultados a sua obsessão; fazer dinheiro é mais divertido que gastá-lo; uma equipe constrói um negócio: um só indivíduo ganha a vida; tenha orgulho das suas realizações, isso é contagioso; é mais fácil implorar por perdão do que pedir permissão. Não saber distinguir entre uma idéia e uma oportunidade também é uma das grandes causas de insucesso. A confusão entre idéia e oportunidade é muito comum entre os empreendedores iniciantes. Identificar e agarrar uma oportunidade é, por excelência, a grande virtude do empreendedor de sucesso. É necessário que o pré-empreendedor desenvolva essa capacidade, praticando sempre. Atrás de uma oportunidade sempre existe uma idéia, mas somente um estudo de viabilidade, que pode ser feito através do Plano de Negócios, indicará seu potencial de transformar-se em um bom negócio (Silva et alii, 2001).

A oportunidade é a fagulha que detona a explosão do empreendedorismo. Há idéias em maior quantidade do que boas oportunidades de negócios. Eis algumas características da oportunidade: é atraente, durável, tem uma hora certa, ancora-se em um produto ou serviço que cria, ou adiciona valor para o seu comprador; apresenta um desafio, que é reconhecer uma oportunidade enterrada em dados contraditórios, sinais, inconsistências, lacunas de informação e outros vácuos, atrasos e avanços, barulho e caos do mercado (quanto mais imperfeito o mercado, mais abundantes são as oportunidades). Reconhecêlas não é uma questão de usar técnicas, check-lists e outros métodos de identificar e avaliar; não há receita de bolo (a literatura tem mais de 200 métodos), mas depende da capacidade do empreendedor (Silva et alii, 2001). 


\section{Educação e Escola}

A capacidade do homem de modificar e ser modificado é que produz história, as diferentes épocas com seus modos de organização social e de produção, particularidades e peculiaridades. Para se alcançar a forma de produção do século XXI, muitas experiências foram vividas, muito conhecimento foi produzido e transmitido. Para realizar esse processo e permitir às gerações utilizarem-se dos conhecimentos e experiências anteriores, sem precisar voltar ao ponto de partida, ocorre a intervenção da educação. Freire (1998) afirma que, [...] A educação é uma forma de intervenção no mundo, mundo este onde o homem vive, age e convive em sociedade, não é um ser isolado, participa de um processo onde influencia e é influenciado pelo grupo, pela sociedade, pela cultura (Freire, 1998, p. 36).

Essa prática não é restrita a uma área. Segundo Libâneo (1994), a educação: [...] corresponde a toda modalidade de influência e inter-relações que convergem para a formação de traços de personalidade social e do caráter, implicando uma concepção de mundo, idéia, valores, modos de agir, que se traduzem em convicções ideológicas, morais, políticas, princípios de ação frente a situações reais e desafios da vida prática (Libâneo, 1994., p. 43). O significado de educação está relacionado a uma prática educativa, a uma ação que ocorre em diferentes lugares de diferentes formas. Ao nascer o ser humano inicia sua interação com a sociedade, relacionando-se com regras e valores. Nesse processo a família torna-se o primeiro núcleo de convivência da criança. Ao lado da família encontram-se outras instituições sociais, que motivadas por interesses diversos, concorrem para o desenvolvimento de atitudes e disseminação de valores. A escola, assim como a família, a religião, os meios de comunicação e outras instituições é um veículo para a prática educativa. A prática desenvolvida pela escola é chamada de prática escolar e é caracterizada como educação intencional ou formal.

A função da escola hoje está vinculada, portanto, às necessidades de nossa época, como exposto na nova Lei de Diretrizes e Bases da Educação - LDB, n. ${ }^{\circ}$ 9394/96, artigo $1^{\circ}$, parágrafo $2^{\circ}$ : "A educação escolar deverá vincular se ao mundo do trabalho e à prática social".

Como forma sistematizada de educação, a prática escolar possui suas ações fundamentadas em teorias pedagógicas, que de forma científica, explicam e instrumentalizam o processo. Diante das exigências para uma nova educação, Ulbricht (1999) afirma que, como qualquer outra empresa, a escola para vencer os contratempos precisa se adaptar, se desenvolver e inovar. $\mathrm{Na}$ adaptação a escola deve adquirir os conhecimentos básicos e as técnicas próprias de sua atividade, que é ensinar ou ainda permitir que o aluno adquira conhecimentos; atualizar as competências e os conhecimentos; manter as competências gerais e detectar e prevenir as perdas de competências. Para adquirir os conhecimentos básicos e as técnicas próprias de sua atividade, é necessário descrever suas atividades e os conhecimentos específicos que necessita para desenvolver estas atividades, difundir as informações e formar seu corpo docente por meio de estágio, supervisão orientada do trabalho ou mesmo trabalho em grupo.

Para atingir o desenvolvimento, torna-se necessário que a escola esteja preocupada em: detectar os potenciais entre seu corpo docente valorizando as competências não utilizadas, gerar novas formas de enriquecimento profissional; detectar e supervisionar 
a superqualificação (a qualificação em excesso é também fonte de frustração gerando especialistas ineficazes) e estimular mantendo o gosto pelo desafio. Finalmente, para que a escola inove é necessário que antecipe novas competências (Ulbricht, 1999). A relação feita aqui entre escola e empresa refere-se ao fato das duas serem um conjunto de pessoas que se reúnem com o objetivo de produzir bens e serviços; que harmoniza capital e trabalho e que está a serviço das pessoas e da comunidade. Assim, como uma das instituições que fazem parte da sociedade, responsável pela prática educativa formal e a inserção de indivíduos em um mundo que passa a exigir um novo perfil de homem, a escola também precisa ultrapassar os seus próprios limites.

\section{Didática e método: fundamentos e objetivos}

Somente a partir do século XVII surge uma preocupação com a atividade de aprendizagem das crianças e jovens, e com as ações deliberadas e planejadas de ensino e foi nesse período que a didática aparece como uma teoria direcionada ao estudo das ligações entre ensino e aprendizagem e as suas leis (Pilelli, 1987). O termo foi consagrado por Comênio (15921670), ao escrever a primeira obra clássica sobre Didática, Didáctica Magna. Segundo Libâneo (1994, p. 27), Comênio foi "o primeiro educador a formular a idéia da difusão dos conhecimentos a todos e criar princípios e regras de ensino". Sua preocupação estava voltada para o desenvolvimento de métodos de instrução mais rápidos e eficientes, uma educação que fosse útil para todos. Para Comênio a tarefa principal da didática era estudar as características de idade e capacidades para o conhecimento, além dos métodos de ensino correspondentes. Em sua origem, denominada como a "arte de ensinar", a didática estava relacionada ao jeito de ensinar, à intuição do professor. Segundo Sanny (1994), a palavra método é originária do grego e significa: = meta (para) + odos (caminho). Por isso a importância de um método adequado em um processo educativo, pois: " $O$ método se refere ao processo completo, compreendendo diversos momentos necessários à consecução de um fim". A sua operacionalização é feita pelo uso de técnicas, como por exemplo, o método ativo que poderá utilizar diferentes técnicas de dinâmica de grupo. Já os procedimentos metodológicos referem-se à maneira de executar algo, à descrição das atividades desenvolvidas pelo professor e às atividades desenvolvidas pelos alunos (Piletti, 1987).

Os métodos são as próprias ações do professor, que organizam as atividades de ensino e aprendizagem, com o intuito de atingir os objetivos do trabalho em relação a um conteúdo. Eles direcionam as formas de interação no processo de ensino, visando à assimilação consciente e o desenvolvimento das habilidades cognitivas e operativas dos alunos. $\mathrm{Na}$ prática educacional didática e método devem ser pensados de forma integrada, com os meios educacionais para acompanhar as mudanças e as exigências sociais. Pereira (2001, p. 34) afirma que "o sistema educacional, responsável pela formação mais ampla do indivíduo, precisa agilizar-se para avançar no ritmo das trocas tecnológicas que acontecem no sistema produtivo".

Assim, quando se consideram os elementos didáticos e metodológicos do processo de aprendizagem da nossa época, tem-se que considerar que esses elementos devem ser utilizados para proporcionar um aprendizado eficaz, sendo inovados e adequados à realidade social. 


\section{Objetivos da prática educativa}

Não há prática educativa sem objetivos, pois são eles que revelam de forma explícita os propósitos definidos quanto ao desenvolvimento das habilidades humanas necessárias a todos os indivíduos, a fim de se capacitarem para enfrentarem as transformações sociais. É preciso, então, encontrar respostas para questões como: Quais as habilidades a serem adquiridas pelos alunos no final do processo?

Ter definido os objetivos no início do processo diminui as chances do trabalho ficar concentrado nos conteúdos, prejudicando o sucesso final dos resultados. Ao definir os objetivos é possível tornar-se mais claro avaliar os resultados da atividade de ensino e mais fácil escolher os procedimentos adequados. Diante da importância dos objetivos na ação didática, Libâneo (1994) assinala algumas recomendações importantes na definição dos mesmos, [...] Especificar conhecimentos, habilidades, capacidades que sejam fundamentais para serem assimiladas e aplicadas em situações futuras, na escola e na vida prática; Observar uma seqüência lógica, de forma que os conceitos e habilidades estejam inter-relacionados, possibilitando aos alunos uma compreensão de conjunto (isto é, formando uma rede de relações na sua cabeça); Expressar os objetivos com clareza, de modo que sejam compreensíveis aos alunos e permitam, assim, que estes introjetem os objetivos de ensino como objetivos seus; Dosar o grau de dificuldades, de modo que expressem desafios, problemas, questões estimulantes e também viáveis; Sempre que possível, formular os objetivos como resultados a atingir, facilitando o processo de avaliação diagnostica e de controle; Como norma geral, indicar os resultados do trabalho dos alunos (o que devem compreender, saber, memorizar, fazer, etc.) (Libâneo, 1994, p. 42).

\section{A ação do professor e a interação professor-aluno}

Como atividade intencional, o trabalho do professor deve ser planejado conscientemente visando atingir objetivos de aprendizagem, e levando em conta os seguintes elementos: os movimentos (ou passos) do processo de ensino no decorrer de uma aula ou unidade didática; os métodos; as formas e os procedimentos de ensino e aprendizagem; os materiais didáticos e as técnicas de ensino; a organização da situação de ensino. A ação do professor é estabelecida a partir da sua concepção pedagógica e entre essas concepções pode-se citar:

A tradicional: "Ensinar é transmitir conhecimentos;

A escolanovista: "Ensinar é criar condições de aprendizagem;

A tecnicista: "O ensino dever se inspirar nos princípios de racionalidade, eficiência e produtividade";

A etimológica: "Ensinar é colocar dentro, gravar no espírito;

Os conteúdos e problemas devem ser colocados aos alunos, de modo a se converterem em desafios a serem superados;

O nível e o volume dos conhecimentos, atividades e exercícios devem estar de acordo 
com o nível e capacidade dos alunos;

As dificuldades apresentadas aos alunos devem ser analisadas pelo professor e trabalhadas didaticamente, com a preocupação de atingir um resultado final;

Conhecimento novo deve ser ligado com o já existente;

Deve haver constante avaliação do progresso alcançado;

Deve haver constante revisão e exercitação dos conhecimentos e habilidades (Libâneo, 1994, p. 48).

Com o objetivo de tornar a aprendizagem mais eficaz, o professor pode estimular e incentivar os alunos, através dos recursos didáticos, dos procedimentos metodológicos, do conteúdo, das atividades práticas e exercícios. A esses estímulos e incentivos, dá-se o nome de motivação. E segundo Piletti (1987), há alguns aspectos importantes relativos à motivação, [...] Se o professor não está motivado, não há condições de motivar os alunos; A falta de motivação para aprender pode ocorrer pela não satisfação de necessidades que antecedem a necessidade do conhecimento; Deve-se levar em conta os fatores que influem no comportamento humano: fatores psicológicos, sociológicos, econômicos, políticos, biológicos e antropológicos; Os fatores socioeconômicos condicionam a motivação, a criatividade e a própria aprendizagem;

O professor não pode considerar o problema de aprendizagem como sendo apenas um processo psicológico (Piletti, 1987, p.57).

Bolzan (1998) mostra que os estudos contemporâneos acerca da motivação trazem ainda conceitos de educadores e psicólogos da década de 70, que de acordo com Carvalho (1972) chegaram às seguintes conclusões:

\section{$[\ldots]$}

a) Não há aprendizagem sem motivação (seja esta consciente ou inconsciente, intrínseca ou extrínseca);

b) Deve haver uma relação positiva entre incentivos e motivos (motivos fortes x ambiente hostil, incentivos inoperantes $\mathrm{x}$ aprendiz com pouca motivação são realidades incompatíveis);

c) Motivação e incentivo são importantes em todas as fases da aprendizagem;

d) Incentivo positivo $\mathrm{x}$ incentivo negativo (elogios funcionam melhor que punição ou censura);

e) A competição pode funcionar como elemento estimulador (a competição entre grupos é preferível à competição individual);

f) O crescimento de incentivos deve aumentar proporcionalmente os motivos, no entanto é preciso ter cuidado para que os incentivos não ultrapassem o limite máximo da capacidade do sujeito;

g) O êxito inicial numa tarefa pode funcionar como fonte de motivação;

h) $\mathrm{O}$ insucesso inicial pode, em alguns casos, servir de estímulo para novas aprendizagens; 
i) Um esforço suspenso ou uma tarefa interrompida pode ser fonte de motivação;

j) A motivação pode aumentar na medida em que o aluno sabe o objetivo de sua tarefa, bem como atribui valor a esse fim;

k) Motivação em excesso pode levar o sujeito a realizar um trabalho abaixo do nível que costuma fazer (Carvalho, 1972 citado por Bolzan, 1998, p.61).

Quanto à interação professor-aluno, existem dois aspectos importantes a serem considerados, os aspectos cognitivos, que dizem respeito à comunicação dos conteúdos e das tarefas, como saber manejar os recursos da linguagem, ter claro o nível de conhecimento dos alunos, ter um plano de aula com objetivos claros e explicar aos alunos o objetivo do conteúdo e os aspectos cognitivos, que se referem aos vínculos emocionais, como combinar autoridade e respeito, manter uma comunicação clara com os alunos, estabelecer normas e orientar a atividade autônoma dos alunos.

\section{Ensino Fundamental}

O Ensino Fundamental compõe, juntamente com a Educação Infantil e o Ensino Médio, a Educação Básica como nomeia a Lei de Diretrizes e Bases da Educação - LDB n. ${ }^{\text {o }}$ 9394/96. É composto por quatro ciclos, sendo:

$1^{\circ}$ Ciclo - $1^{\mathrm{a}}$ e $2^{\mathrm{a}}$ séries;

$2^{\circ}$ Ciclo - $3^{\mathrm{a}}$ e $4^{\mathrm{a}}$ séries;

$3^{\circ}$ Ciclo - $5^{\mathrm{a}}$ e $6^{\mathrm{a}}$ séries;

$4^{\circ}$ Ciclo $-7^{\mathrm{a}}$ e $8^{\mathrm{a}}$ séries.

Conforme expressa a LDB, o Ensino Fundamental no Brasil objetiva garantir a formação básica do indivíduo mediante:

$[\ldots]$

I - O desenvolvimento da capacidade de aprender, tendo como meios básicos o pleno domínio da leitura, da escrita e do cálculo;

II - A compreensão do ambiente natural e social, do sistema político, da tecnologia, das artes e dos valores em que se fundamenta a sociedade;

III - O desenvolvimento da capacidade de aprendizagem, tendo em vista a aquisição de conhecimentos e habilidades e a formação de atitudes e valores;

IV - O fortalecimento dos vínculos de família, dos laços de solidariedade humana e tolerância recíproca em que se assenta a vida social" (LDB, 1996).

O Ensino Fundamental de acordo com os Parâmetros Curriculares Nacionais (PCN) deve proporcionar os meios necessários para que os alunos sejam capazes de:

a) Compreender a cidadania como participação social e política, assim como exercício de direitos e deveres políticos, civis e sociais, adotando, no dia a dia, atitudes de solidariedade, cooperação e repúdio às injustiças, respeitando o outro e exigindo para si o mesmo respeito; 
b) Posicionar-se de maneira crítica, responsável e construtiva nas diferentes situações sociais, utilizando o diálogo como forma de mediar conflitos e de tomar decisões coletivas;

c) Conhecer características fundamentais do Brasil nas dimensões sociais, materiais e culturais como meio para construir progressivamente a noção de identidade nacional e pessoal e o sentimento de pertinência ao país;

d) Conhecer e valorizar a pluralidade do patrimônio sociocultural brasileiro, bem como aspectos socioculturais de outros povos e nações, posicionando-se contra qualquer discriminação baseada em diferenças culturais, de classe social, de crenças, de sexo, de etnia ou outras características individuais e sociais;

e) Perceber-se integrante, dependente e agente transformador do ambiente, identificando seus elementos e as interações entre eles, contribuindo ativamente para a melhoria do meio ambiente;

f) Desenvolver o conhecimento ajustado de si mesmo e o sentimento de confiança em suas capacidades afetiva, física, cognitiva, ética, estética, de inter-relação pessoal e de inserção social, para agir com perseverança na busca de conhecimento e no exercício da cidadania;

g) Conhecer o próprio corpo e dele cuidar, valorizando e adotando hábitos saudáveis como um dos aspectos básicos da qualidade de vida e agindo com responsabilidade em relação à sua saúde e à saúde coletiva;

h) Utilizar as diferentes linguagens - verbal, musical, matemática, gráfica, plástica e corporal, como meio para produzir, expressar e comunicar suas idéias, interpretar e usufruir das produções culturais, em contexto públicos e privados, atendendo às diferentes intenções e situações de comunicação;

i) Saber utilizar diferentes fontes de informação e recursos tecnológicos para adquirir e construir conhecimentos;

j) Questionar a realidade formulando-se problemas e tratando de resolvê-los, utilizando para isso o pensamento lógico, a criatividade, a intuição, a capacidade de análise crítica, selecionando procedimentos e verificando sua adequação (PCN, 1998, p. $15)$.

\section{Empreendedorismo e educação}

A escola, espaço onde ocorre a prática educacional formal e intencional, como ambiente aberto para a construção e o exercício das aptidões cognitivas e atitudinais necessárias para a compreensão do conhecimento, torna-se uma fonte fundamental na disseminação do espírito empreendedor (Sebrae, 2009).

O empreendedorismo trabalhado no ambiente escolar contribui para o desenvolvimento de crianças e adolescentes capazes de pensar, de fazer e de criar com autonomia e flexibilidade, competências necessárias para que possam desbravar, compreender e fazer uso desse mar de conhecimentos existentes (Sebrae, 2009). Para desenvolver o empreendedorismo na prática escolar é necessário, portanto, considerar os componentes didáticos e metodológicos que permeiam esse processo educacional. É também fundamental que haja um programa que una a base teórica e a vivência prática e que levem em conta as mudanças, para adaptar os procedimentos à realidade atual. Hoje os conhecimentos enciclopédicos já não são mais necessários, nem tampouco as técnicas e os processos mecânicos (SEBRAE, 2009). 
Estudo sobre a Viabilidade da Implantação Formal do Ensino de Empreendedorismo na Rede Municipal de Ensino Fundamental no Município de Vassouras-RJ Tatiana Nunes Coelho Ramos - Margareth Fernandes

Artigo de Demanda Contínua

O professor então adquire um novo papel, que é o de possibilitar condições de aprendizagem para a aquisição das novas habilidades e competências pelos alunos. Preocupados com essas questões, muitos estudiosos e pesquisadores apontam para novas propostas educacionais e entre eles, Barreto (1998), que sugere o seguinte enfoque na educação empreendedora:

[...]

a) Valorizar a sensibilidade intuitiva;

b) Compreender os valores transmitidos;

c) Reconhecer as metas diferentes dos indivíduos do grupo;

d) Tomar decisões baseadas em julgamentos de confiança e na competência das pessoas;

e) Buscar ajustar a prática aos princípios da sociedade;

f) Desenvolver a solução mais apropriada sob pressão de tempo;

g) Aprender fazendo e fora da sala de aula;

h) Vislumbrar informações pessoalmente prospectadas as de qualquer fonte, ponderando seu valor;

i) Avaliar o julgamento de pessoas e eventos via "retrocomunicação direta";

j) Possibilita sucesso no aprendizado medido ao resolver problemas e na experiência do fracasso. (Barreto, 1998, p. 21)

\section{Metodologia do Ensino}

A disseminação do empreendedorismo na educação, com o desenvolvimento de habilidades empreendedoras em crianças e adolescentes requer a utilização de procedimentos metodológicos adequados, conduzindo os alunos a "aprender empreendendo". Os procedimentos metodológicos propostos são sintetizados em sete etapas que convergem para um caminho: o do desenvolvimento de habilidades empreendedoras em crianças e adolescentes, por meio do planejamento, organização e execução de um evento festivo. As etapas utilizadas são:

$1^{\text {a }}$ etapa: Ideia Inicial

$2^{a}$ etapa: Validação da Ideia

$3^{\mathrm{a}}$ etapa: Como Fazer

$4^{\mathrm{a}}$ etapa: Parceria

$5^{\mathrm{a}}$ etapa: Execução

6 etapa: Avaliação

$7^{\mathrm{a}}$ etapa: Recomeçar

$\mathrm{Na}$ primeira etapa, os problemas da comunidade escolar são transformados em oportunidades e desafios estimulantes para atitudes criativas e inovadoras. É o momento da idéia inicial em que tudo é possível e deve ser aceito pelo grupo. No segundo passo, inicia-se o processo de filtro em que ocorre a validação de idéias, de acordo com o mercado-alvo selecionado para pesquisa. Nesse caso o ambiente para o desenvolvimento 
de habilidades favorece principalmente a atitude de busca de informação. Prontos para o próximo passo, o grupo desenvolve alternativas para a realização do processo produtivo. O sonho e as idéias tornam-se possíveis com ênfase na habilidade de discriminação de informações para o planejamento do como fazer. O grupo vai para o quarto passo, concretizando suas idéias por meio de parcerias em que a exigência para o sucesso é proporcional ao desenvolvimento da habilidade de negociar. A partir daí (quinto passo), o grupo deve estar preparado para executar o empreendimento. A execução exige entre outras a habilidade de negociar, pois é no acontecer que as decisões e avaliações devem ser rápidas e coerentes. Embora a avaliação conste como sexto passo do procedimento metodológico junto com as habilidades de organização das informações coletadas a partir do resultado final, é importante ressaltar que na sequência lógica dos passos e na didática da aplicação, os procedimentos são organizados de maneira a enfatizar a dialética da ação e/ou representação da realidade. Por isso, o sétimo passo, o recomeçar indica que o processo é interminável, ou que o final de um empreendimento caracterizase pela percepção de oportunidades de novos desafios. Esses devem ser os indicadores de que a sobrevivência do projeto inicial precisará de adequações constantes. $\mathrm{O}$ início de outros projetos dependerá das oportunidades identificadas e das novas idéias que surgirão enriquecidas pela experiência adquirida. Diante das informações gerais, será agora realizada uma descrição das técnicas e estratégias utilizadas em cada passo. Essa descrição demonstrará a flexibilidade dos procedimentos propostos, permanecendo o objetivo de desenvolver habilidades empreendedoras, se adaptando ao empreendimento escolhido.

\section{Preparação para as sete etapas}

Ao desenvolver um trabalho é preciso obter informações sobre o público e o local. É preciso saber quem são os alunos com quem se vai trabalhar, a faixa etária, as expectativas, as necessidades do público, a situação econômica e cultural. As informações coletadas serão uma referência para a adequação da metodologia. Esta avaliação inicial, denominada de Avaliação Diagnóstica, fornece informações básicas para começar o trabalho, aproximando a ação a ser realizada da realidade e das necessidades dos alunos. Também durante o processo é fundamental obter um feedback por meio da realização de avaliações constantes, chamadas formativas, de todos os encontros.

\section{Avaliação diagnóstica do local}

Sobre o local no qual irá se desenvolver um trabalho é importante saber quais os recursos materiais e humanos disponíveis; a localização geográfica para possíveis pesquisas de campo; a organização e o funcionamento, tais como horários e pessoas responsáveis para negociação e planejamento de uso.

Essas informações são importantes na antecipação e no planejamento do trabalho, indicando o que há de disponível e o que precisa ser adquirido ou providenciado. $\mathrm{Na}$ avaliação diagnóstica do local são utilizados alguns instrumentos como pesquisas, entrevistas, contatos com pessoas responsáveis pela organização e manutenção, etc. 


\section{Avaliação diagnóstica do público específico}

Uma das principais questões de um trabalho é saber as características do público alvo, suas expectativas e anseios. A avaliação diagnóstica do público específico, aquele com quem se terá contato direto, pode ser realizada por meio de entrevistas e pesquisas. A avaliação diagnóstica do público na preparação para o desenvolvimento dos procedimentos metodológicos objetiva definir o grupo do projeto, os nomes e a faixa etária.

\section{Avaliação Formativa}

A execução de um trabalho é permeada por situações não-planejadas e isso requer uma postura flexível e organizada. Ordenar e aproveitar os imprevistos é realizar uma avaliação constante dos alunos, chamada de "formativa". Por meio dessa avaliação são obtidas informações sobre as compreensões e as dúvidas dos alunos e serão essas informações que orientarão o ritmo do trabalho, tornando o processo mais dinâmico e inovador.

\section{Propostas}

Por mais grandiosa que seja, a tarefa de inserir o aprendizado de empreendedorismo no nível fundamental, é apenas um passo no caminho da criação de uma cultura empreendedora que dará suporte ao processo de desenvolvimento econômico. E o que precisa ser feito pelo conjunto das forças da nossa sociedade, proposto pelo artigo:

1 - propagar o ensino de empreendedorismo para todos os níveis educacionais. A universidade é o ponto de partida porque ela é uma forte formadora de opinião e multiplicadora do saber. Mas é preciso disseminar a cultura empreendedora desde o primeiro degrau do sistema educacional, o ensino fundamental, porque só iremos criar o que chamamos de "incubadora social", quando toda a sociedade estiver envolvida por uma cultura que sinalize positivamente para valores empreendedores que priorizam a geração e distribuição de riquezas, a inovação, a cidadania, a ética a liberdade em todos os níveis, o respeito ao homem e ao meio ambiente;

2 - estimular a pesquisa na área de empreendedorismo. É importante que seja criado um Congresso Brasileiro de Empreendedorismo, a fim de estimular a pesquisa na área e seja o ponto de encontro de todos aqueles envolvidos com o empreendedorismo, como a comunidade acadêmica, praticantes, empreendedores, sistemas de suporte e que promova um permanente intercâmbio com pesquisadores de todo o mundo;

3 - sensibilizar os sistemas de suporte e as forças sócio-político-econômicas para a necessidade de se apoiar as empresas emergentes. Esta não é uma tarefa isolada de um segmento específico, mas de toda a sociedade. Já ouvimos autoridades governamentais dizerem que a pequena empresa é problema só do Sebrae; nada mais enganoso. É umproblema, ou melhor, uma solução que toda a sociedade tem que perseguir porque ela é a base do desenvolvimento econômico. Estamos falando de 4,5 milhões de empresas, $98 \%$ das empresas nacionais, que envolvem uma massa de 60 milhões de pessoas e hoje representa $20 \%$ do PIB nacional;

4 - implantar políticas públicas e legislação de apoio. A importância política da pequena 
empresa não corresponde à sua importância econômica e social. A legislação que pode corrigir este descompasso tem um lento tratamento no Congresso Nacional;

5 - estimular a criação de incubadoras e parques tecnológicos e científicos. A empresa do conhecimento, força econômica desta era, nasce da integração dos trabalhos de pesquisadores e empreendedores. O Brasil tem que investir pesadamente neste setor;

6 - preparar as empresas existentes para a formulação estruturada de suas demandas aos centros de alta tecnologia. É necessário que as empresas de base tecnológica saibam formular demandas aos centros de pesquisa universitários. O instrumento fundamental é a utilização intensiva da metodologia de Planos de Negócios, que indicam as necessidades da tecnológica dominada pelos centros e também possibilitam a formação de parcerias com empresas surgidas do ambiente universitário. A viabilização deste processo será muito bem conduzida se for assumida pelos órgãos de representação empresarial de cada categoria;

7 - Visitas a USEN - Universidade Sebrae de Negócios. O nome Universidade é muito mais abrangente, para expressar a universalidade na forma de educação avançada, aprofundada e dirigida ao ensino de alunos empreendedores. A USEn usa uma metodologia de fazer com que o aluno passe por uma mudança de atitude e ele mesmo encontre o seu caminho ou forma de como ele quer aprender. Também aqui é fundamental a ação propulsora e educadora do poder público.

\section{Considerações Finais}

Assim como Fayol (1989) mostrou ser possível ensinar os princípios da administração, a arte de empreender deixou de ser considerada um dom e hoje o empreendedorismo é uma disciplina que apresenta modelos, processos, base teórica, estudos de caso e um alto nível de convergência interdisciplinar. A relevância da habilidade de empreender permite que o tema seja propagado e ensinado em outras áreas de formação profissional que exijam a capacidade de criação e de ajustes frente às mudanças aceleradas do ambiente.

Hoje a economia mundial opera com novos padrões de relações de trabalho, onde a estabilidade profissional se posiciona longe da realidade encontrada no mercado. Os desafios a serem enfrentados dizem respeito não só às mudanças de metodologia de ensino, mas também à conscientização do corpo discente e docente que o melhor método de aprendizagem a ser adotado pressupõe o comprometimento e integração de todos. A interdisciplinaridade aqui, enquanto técnica pedagógica de convergência de conhecimentos, pode vir a ser um instrumental eficiente no processo de formação do aluno. Ela possibilita ao aluno, no decorrer de sua formação, pesquisar temas ligados às disciplinas centrais de cada ano e associar o conteúdo programático das demais disciplinas em um grande projeto científico. Esta estrutura pedagógica facilita a inserção de uma base filosófica que a instituição de ensino queira impor no seu processo educacional.

No caso específico deste artigo, a proposta educacional tem como pano de fundo a formação do aluno empreendedor. Pode-se afirmar, no entanto, que a viabilidade de um projeto desta natureza, fica facilitada em todas as instituições de ensino, seja ela pública ou privada, uma vez que, a flexibilidade de mudança dos processos organizacionais 
Estudo sobre a Viabilidade da Implantação Formal do Ensino de Empreendedorismo na Rede Municipal de Ensino Fundamental no Município de Vassouras-RJ

Tatiana Nunes Coelho Ramos - Margareth Fernandes

Artigo de Demanda Contínua

elas existem em todos os níveis. Ou seja, com a necessidade de empreendedores e as instituições possuindo os melhores alunos, professores e diretores, os procedimentos de mudança na concepção da idéia, de inserção dos temas e disciplinas emergentes na grade curricular, encontram-se facilitados. 
Estudo sobre a Viabilidade da Implantação Formal do Ensino de Empreendedorismo na Rede Municipal de Ensino Fundamental no Município de Vassouras-RJ

\section{Referências}

Barreto, Luiz Pondé. (1998). Educação para o Empreendedorismo. Núcleo para Estudos do Empreendedorismo, Universidade de Salvador - Salvador.

Bolzan, Regina de Fátima Fructuoso de Andrade. (1998). Conhecimento tecnológico e o paradigma educacional. Dissertação do Curso de Mestrado em Engenharia de Produção. Florianópolis: Universidade Federal de Santa Catarina.

Brasil. Presidência da República. Casa Civil. Subchefia para Assuntos Jurídicos. Lei de Diretrizes e Bases da Educação Nacional - no 9.394/96, de 20/12/1996.

Brasil. Parâmetros Curriculares Nacionais: $3^{\circ}$ e $4^{o}$ ciclos do Ensino Fundamental: Língua Portuguesa. Brasília/DF: MEC/SEF.

Carvalho, I. M. (1972). O processo didático. Rio de Janeiro: FGV.

Comênio, João Amós. (1957). Didática Magna. Trad. Joaquim Ferreira Gomes. $4^{\mathrm{a}}$ ed. Lisboa: Fundação Calouste Gulbenkian.

Dolabela, Fernando Celso. (1999). O Segredo de Luísa. São Paulo: Ed. Cultura Editores Associados..

Drucker, Peter Ferdinand. (2002). Inovação e espírito empreendedor (entrepreneurship): prática e princípios. Tradução de Carlos Malferrari. São Paulo: Pioneira Thompson.

Fayol, Henri. (1989). Administração Industrial e Geral: previsão, organização, comando, coordenação e controle. 10 ed. São Paulo: Atlas.

Freire, Paulo. (1998). Pedagogia da autonomia: saberes necessários à prática educativa. São Paulo: Paz e Terra.

Hornaday J. A. (1982). Research about living entrepreneurs. In: KENT, C. A. et al. (Eds.). Encyclopedia of entrepreneurship, Englewood Cliffs: Prentice-Hall, p. 20-34.

Libâneo, José Carlos. (1994). Didática. São Paulo: Cortez.

Pereira, S. M. (2001). A formação do empreendedor. Tese de doutorado da Universidade Federal de Santa Catarina, UFSC.

Pessoa, Marcos de Lacerda. (2010). BEL-i9: empreendendo e inovando em rede para o desenvolvimento Sustentável. Curitiba: Companhia Paranaense de Energia/COPEL.

Piletti, Claudino. (1987). Didática Geral. São Paulo: Ática.

Sanny, Rosa. (1994). Construtivismo e Mudança. São Paulo: Cortez.

Serviço Brasileiro de Apoio às Micro e Pequenas Empresas (SEBRAE). (2009). Apostilas Programa Novos Jovens Empreendedores. São Paulo: Sebrae.

Schumpeter, J.A. (1982). Teoria do desenvolvimento econômico: uma investigação sobre lucros, capital, crédito, juro e o ciclo econômico. São Paulo: Abril Cultural.

Smith, Adam. (1981). Uma investigação sobre a natureza e causa da riqueza das nações. Livro 1. São Paulo: Hemus.

Silva, Nilson Carlos Duarte da; Colenci Jr., Alfredo; Torkomian, Ana Lúcia Vitale. (2001). Ensino superior e a formação do profissional do empreendedor de sucesso. Encontro de Engenharia de Produção, 2001, Salvador. Anais eletrônicos. Salvador: ENEGEP. 
Estudo sobre a Viabilidade da Implantação Formal do Ensino de Empreendedorismo na Rede Municipal de Ensino Fundamental no Município de Vassouras-RJ Tatiana Nunes Coelho Ramos - Margareth Fernandes

Artigo de Demanda Contínua

Timmons, J.A. (1994). New venture creation. Boston: Irwin McGraw-Hill, 4. ed.

Ulbricht, Vânia Ribas. (1999). A Criatividade e o Empreendedorismo. In Anais: Enempre, p.161-165.

www.usen.com.br, 11/09/2010, 19h15min.

www.sebrae.com.br/br/home/index.asp, 11/09/2010, 20h40min. 